\title{
Electrochemical characterization of activated carbon-sulfur composite electrode in organic electrolyte solution
}

\author{
Dongyoung Kim ${ }^{1}$, Soo-Jin Park ${ }^{2}$, Yongju Jung ${ }^{3}$, Seok Kim ${ }^{1, \star}$ \\ ${ }^{1}$ Department of Chemical and Biochemical Engineering, Pusan National University, San 30, Jangjeon-dong, Geumjeong-gu, Busan \\ 609-735, Republic of Korea \\ ${ }^{2}$ Dept. of Chemistry, Inha University, 253, Yonghyun-dong, Nam-gu, Incheon 402-751, Korea \\ ${ }^{3}$ Dept. of Applied Chemical Engineering, Korea University of Technology and Education, 307, Gajeon-ri, Byeongcheon, Cheonan-si, \\ Chungnam-do, 330-708, Korea
}

\section{Article Info \\ Received 7 January 2013 \\ Accepted 16 February 2013}

*Corresponding Author

E-mail: seokkim@pusan.ac.kr

Tel: $+82-51-510-3874$

\section{Open Access}

DOI: http://dx.doi.org/

10.5714/CL.2013.14.2.126

This is an Open Access article distributed under the terms of the Creative Commons Attribution Non-Commercial License (http://creativecommons.org/licenses/ by-nc/3.0/) which permits unrestricted non-commercial use, distribution, and reproduction in any medium, provided the original work is properly cited.

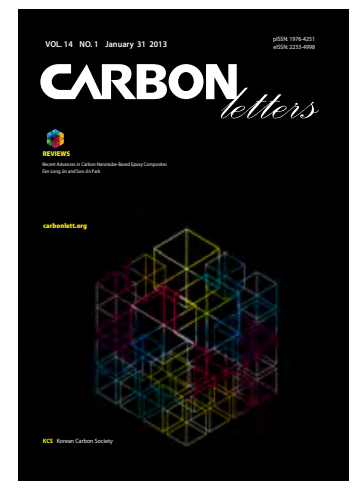

http://carbonlett.org

pISSN: 1976-4251

elSSN: 2233-4998

Copyright $\odot$ Korean Carbon Society

\begin{abstract}
In this study, we present a more electrochemically enhanced electrode using activated carbon (AC)-sulfur (S) composite materials, which have high current density. The morphological and micro-structure properties were investigated by transmission electron microscopy. Quantity of sulfur was measured by thermogravimetric analysis analysis. The electrochemical behaviors were investigated by cyclic voltammetry. As a trapping carbon structure, AC could provide a porous structure for containing sulfur. We were able to confirm that the AC-S composite electrode had superior electrochemical activity.
\end{abstract}

Key words: activated carbon, nanocomposite, lithium-sulfur, electrochemical

\section{Introduction}

Lithium-ion rechargeable batteries (LIBs) have been developed as portable power sources for a wide variety of electronic devices and as power batteries for electric vehicles (EVs) or hybrid electric vehicles (HEVs). The market demand for LIBs has been growing because of their competitive advantages of high energy density and light weight; this will only lead to further improvements. At present, lithium transition metal oxides, especially $\mathrm{LiCoO}_{2}$, are the most successful cathode materials on the consumer market. However, the specific energy ranges of lithium transition metal oxides, which are only specific capacity (100-200 $\left.\mathrm{mAhg}^{-1}\right)$, will not meet the increasing demands of electronic devices. In addition, safety issues regarding lithium metal oxide cathodes are critical because of the cathodes' intrinsic thermal properties, e.g. fully charged lithium cobalt oxide can release oxygen, which oxidizes the solvent to cause battery thermal runaway. Moreover, cobalt is toxic and expensive. The insufficiencies in current cathode materials limit their applications in future usage, such as in large-scale batteries to power EVs and HEVs. Sulfur (S) has a strong potential to work as a cathode active material in rechargeable lithium batteries [1-4].

Sulfur accepts two electrons per formula unit in electrochemistry and exhibits higher theoretical specific capacity $\left(1675 \mathrm{mAhg}^{-1}\right)$ and higher theoretical specific energy $\left(2600 \mathrm{mWhg}^{-1}\right.$ with lithium anode) than any other known cathode active material [5-9]. Furthermore, sulfur is abundant in various minerals, cheap, and environmentally friendly. Therefore, there have been many scientific studies to develop Li-S batteries [10-19]. However, the poor cycle life of Li-S batteries has been a significant obstacle toward their commercialization. During the cycle, fast capacity fading occurs due to a variety of factors, including the dissolution of intermediate lithium polysulfide products $\left(\mathrm{Li}_{2} \mathrm{~S}_{\mathrm{x}}, 4 \leq \mathrm{x} \leq 8\right)$ in the electrolyte, large volumetric expansion of sulfur $(\sim 80 \%)$ during cycle, and the insulating nature of $\mathrm{Li}_{2} \mathrm{~S}$. In order to improve the cycle life of $\mathrm{Li}-\mathrm{S}$ batteries, the dissolution of polysulfides is a key problem. Polysulfides are soluble in the electrolyte and can 


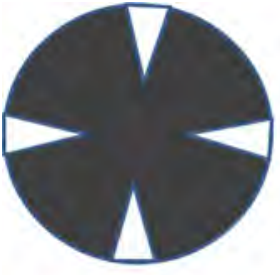

Dried AC

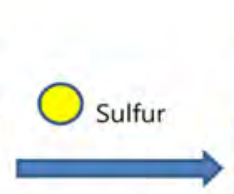

Infiltration

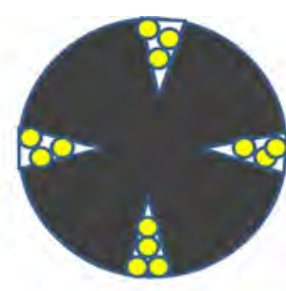

S-Impregnated AC
Fig. 1. Schematic description of infiltration method for preparation of activated carbon-sulfur (AC-S) composite.

diffuse to the lithium anode, resulting in undesired parasitic reactions. The shuttle effect also leads to random precipitation of $\mathrm{Li}_{2} \mathrm{~S}_{2}$ and $\mathrm{Li}_{2} \mathrm{~S}$ on the positive electrode, which dramatically changes the electrode morphology and results in fast capacity fading. As a result, efficient trapping of polysulfides is highly desired for improving the cycle life of Li-S batteries.

In the study, we introduce the preparation of a composite electrode for Li-S batteries. Activated carbon (AC) is a promising carbon structure. AC is easily produced; it is also abundant in various materials, cheap, and environmentally friendly. The purpose of this study is to present an electrochemically enhanced cathode using AC-S composite materials that have high electrochemical behavior. Another purpose of this study is to look at the electrochemical property by characterizing composite electrodes in organic electrolytes.

\section{Experiment Details}

\subsection{Synthesis of AC-S composite}

In Fig. 1, AC-S composite was synthesized using the infiltration method. We used MSP-20 material as the source of AC. MSP-20 is known as an active material for super capacitors. At first, $3 \mathrm{~g}$ of MSP-20 was heated at $140^{\circ} \mathrm{C}$ in air in a muffle furnace and cooled to room temperature. Then, we were able to obtain dried MSP-20 as an elementary material. We prepared a $20 \mathrm{~mL}$ vial. We poured $5 \mathrm{~mL}$ of carbon disulfide solution into the mixture of $0.5 \mathrm{~g}$ of MSP-20 and $0.05 \mathrm{~g}$ of sulfur. The mixture was stirred and sonicated. After that, the mixture was heated at $30^{\circ} \mathrm{C}$ in a hood in order to dry the solution. We placed the mixture in a muffle furnace and the mixture was heated at $140^{\circ} \mathrm{C}$ for drying. Then, we were able to obtain the mixture as an active material for electrochemical measurement.

\subsection{Preparation of electrodes}

All electrochemical tests were done in a three electrode system. We prepared two types of electrodes. One type of electrode was a glassy carbon electrode (GCE); the other type of electrode was an aluminum foil ( $\mathrm{Al}$ foil) electrode.

To prepare the GCE, working electrodes were prepared as follows. $5 \mathrm{mg}$ of active material was added to $0.5 \mathrm{~mL}$ of distilled water. The mixture was sonicated. After that, $0.1 \mathrm{~mL}$ of Nafion was added to the mixture and sonicated. Then, we were able to obtain the mixture as slurry samples. $0.3 \mu \mathrm{L}$ of the samples were placed on

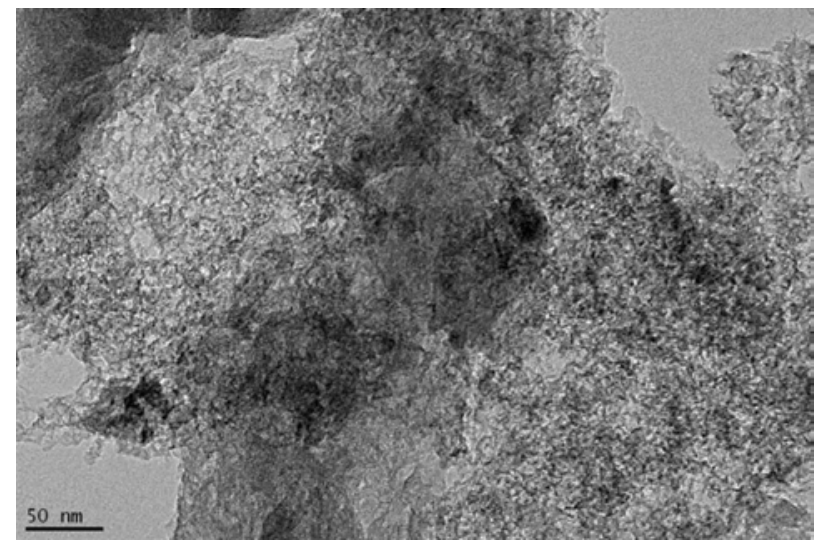

Fig. 2. Transmission electron microscopy image of MSP-20.

the GCE and used as a working electrode. Then, the sample-coated electrode was dried at $60^{\circ} \mathrm{C}$ in a drying oven. Finally, we were able to obtain the sample-coated GCE for electrochemical measurement.

To prepare the $\mathrm{Al}$ foil electrode, working electrodes were prepared as follows. $0.04 \mathrm{~g}$ of active material was prepared in the mortar. $0.005 \mathrm{~g}$ of Super-P carbon black as a conductive material and $0.005 \mathrm{~g}$ of polyvinylidene fluoride were added in a mortar. We poured a small amount of N-Methyl-2-pyrrolidone into the mixture. After that, we prepared slurry samples by mixing. The samples were placed on Al foil and sample-coated Al foil was dried in an oven. Finally, we were able to obtain the samplecoated $\mathrm{Al}$ foil electrode for electrochemical measurement.

\subsection{Morphological and physical measurements}

The morphology and the nanostructures of the samples were investigated using transmission electron microscopy (TEM, JEOL-2010). The quantity of sulfur was measured by thermogravimetric analysis (TGA) analysis (SDT Q600 V8.3 Build 101).

\subsection{Electrochemical measurements}

We used a platinum rod as a counter electrode; a saturated calomel electrode (SCE) was used as a reference electrode. We prepared the electrolytes as follows. $0.5 \mathrm{M}$ of $\mathrm{LiPF}_{6}$ as a lithium salt was added to dimethylformamide (DMF) solution. The mixture was stirred until the salt was dissolved completely.

The electrochemical measurements were carried out in the prepared electrolytes at room temperature using an Iviumstat (Ivium Technologies, The Netherlands). Cyclic voltammetry (CV) tests were performed for 5 cycles between -2.8 and $+1.0 \mathrm{~V}$ at $10 \mathrm{mVs}^{-1}$ of scan rate $[15,20]$.

\section{Results and Discussion}

\subsection{AC-S nanocomposite characterization}

Morphological properties of the composite were analyzed by considering the TEM images. Fig. 2 shows the TEM image of MSP-20. Fig. 3 shows the TEM image of the MSP-20-S01 com- 


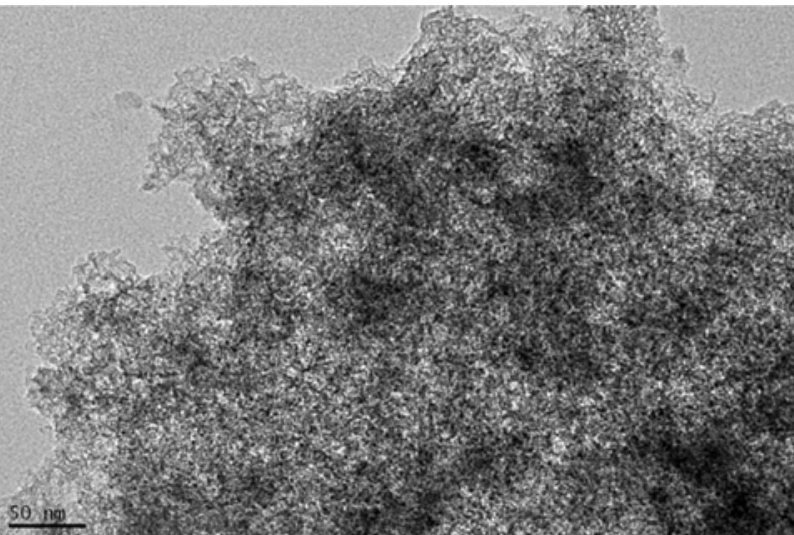

Fig. 3. Transmission electron microscopy image of MSP-20-S01 composite.

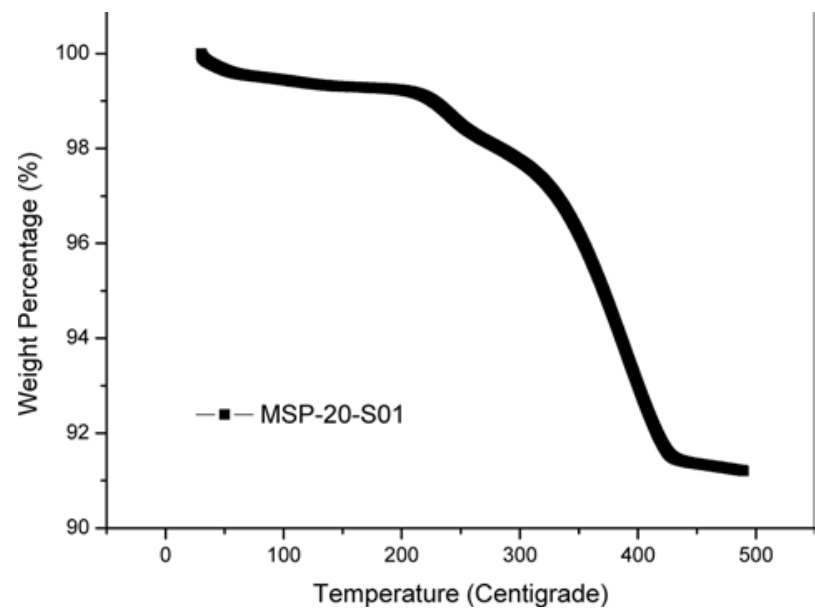

Fig. 4. Thermogravimetric analysis of MSP-20-S01 in nitrogen with heating rate of $10^{\circ} \mathrm{C} / \mathrm{min}$. Line represents the weight percentage (\%) vs. temperature.

posite.

Elemental sulfur was loaded into MSP-20 through liquid phase infiltration by using sulfur solution in carbon disulfide $\left(\mathrm{CS}_{2}\right)$. The infiltration of sulfur in MSP-20 was carried out through a solution impregnation and drying procedure to attain samples with various loadings using a $10 \mathrm{wt} \%$ sulfur solution in $\mathrm{CS}_{2}$. The solvent carbon disulfide was evaporated in a vented hood. After impregnation and drying, samples were annealed at $140^{\circ} \mathrm{C}$. The annealing step stripped away the residual $\mathrm{CS}_{2}$. The resulting samples are denoted as MSPO-20-S01, with sulfur loading of $9 \mathrm{wt} \%$ determined by TGA in nitrogen. Shown in Fig. 4 is the TGA curve of the MSP-20-S01 composite. At a fixed heating ramp of $10^{\circ} \mathrm{C} / \mathrm{min}$, the evaporation rate of the sulfur from the MSP-20-S01 composite can be used as indirect evidence to locate the sulfur loaded on the porous carbon.

\subsection{Electrochemical characterization}

Electrochemical performance characterizations of electrodes were performed using CV. Figs. 5-8 show cyclic voltammograms of the samples during the cycle test. The samples were

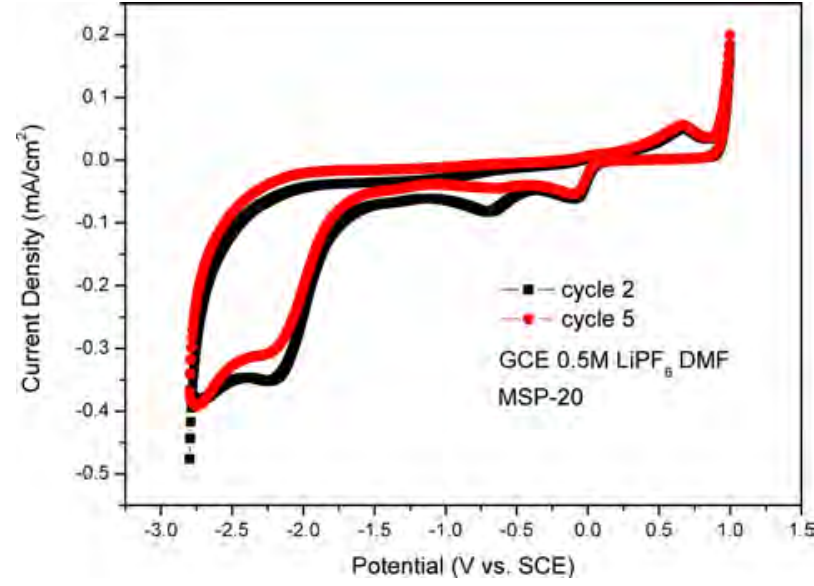

Fig. 5. Cyclic voltammograms of glassy carbon electrode (GCE) in case of MSP-20 during the cycle test in dimethylformamide (DMF) solution containing $0.5 \mathrm{M} \mathrm{LiPF}_{6}$. The samples were analyzed between -2.8 and +1.0 $\mathrm{V}$ with $10 \mathrm{mVs}^{-1}$ of scan rate. SCE: saturated calomel electrode.

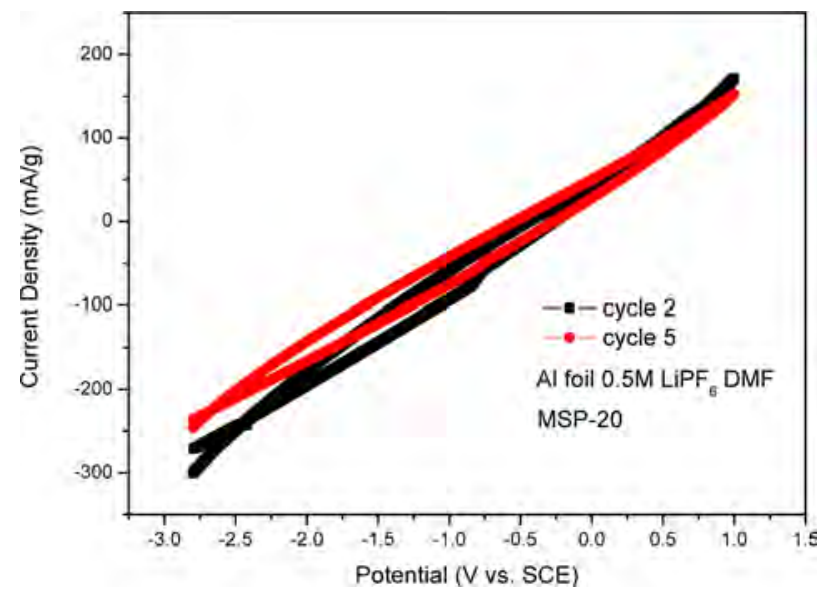

Fig. 6. Cyclic voltammograms of Al foil electrode in case of MSP-20 during the cycle test in dimethylformamide (DMF) solution containing $0.5 \mathrm{M}$ $\mathrm{LiPF}_{6}$. The samples were analyzed between -2.8 and $+1.0 \mathrm{~V}$ with $10 \mathrm{mVs}^{-1}$ of scan rate. SCE: saturated calomel electrode.

analyzed between -2.8 and $+1.0 \mathrm{~V}$ at $10 \mathrm{mVs}^{-1}$ of scan rate. We carried out tests for 5 cycles.

For the data shown in Fig. 5, we used a GCE as an electrode. There was MSP-20 on the GCE as an active material. Fig. 5 shows one oxidation peak and three reduction peaks. The oxidation peak is located at $+0.67 \mathrm{~V}$ and the reduction peaks are located at $-2.21 \mathrm{~V},-0.69 \mathrm{~V}$, and $-0.09 \mathrm{~V}$. In Fig. 5, in the cathodic process (i.e., the backward scan), the peak current density of cycle 2 is lower than that of cycle 5 . This means that electroactivity decreases during the cycle test.

In Fig. 6, we used Al foil as an electrode. There was MSP-20 on the $\mathrm{Al}$ foil as an active material. Fig. 6 shows one reduction peak. The reduction peak is located at $-0.83 \mathrm{~V}$. In Fig. 6 , in the cathodic process (i.e., backward scan), the peak current density of cycle 2 can be seen to be lower than that of cycle 5 . This means that electroactivity decreases during the cycle test. The $\mathrm{CV}$ graph of cycle 5 has a slighter incline than that of cycle 2 .

In Fig. 7, we used a GCE as an electrode. There was MSP- 


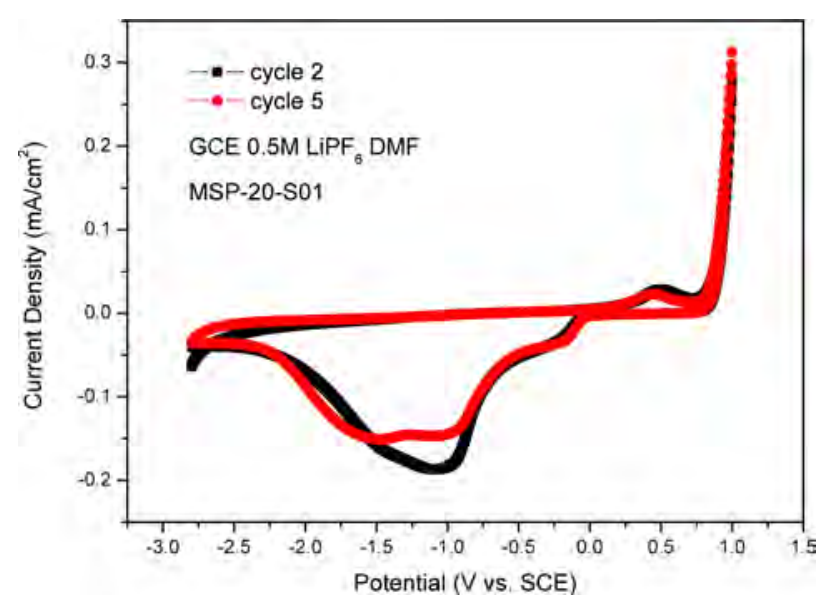

Fig. 7. Cyclic voltammograms of glassy carbon electrode (GCE) in case of MSP-20-S01 during the cycle test in dimethylformamide (DMF) solution containing $0.5 \mathrm{M} \mathrm{LiPF}_{6}$. The samples were analyzed between -2.8 and +1.0 $\mathrm{V}$ with $10 \mathrm{mVs}^{-1}$ of scan rate. SCE: saturated calomel electrode.

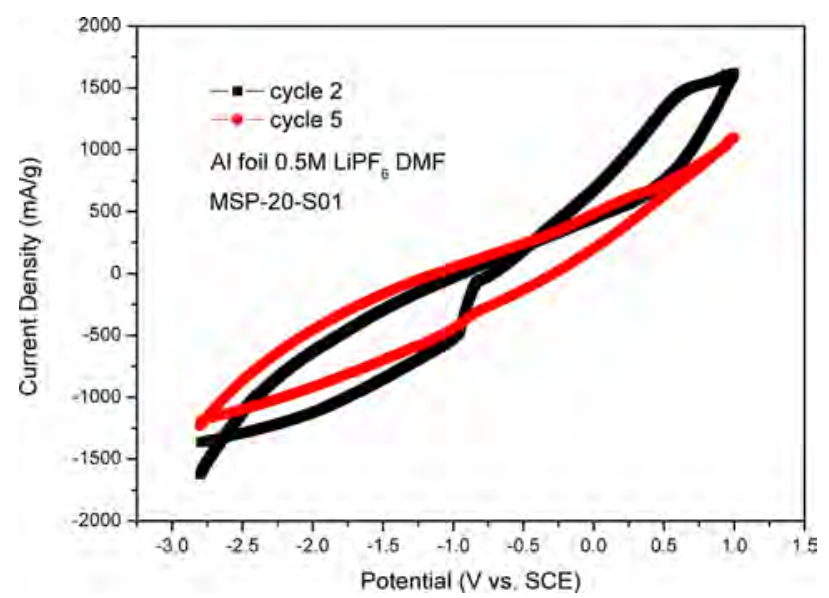

Fig. 8. Cyclic voltammograms of Al foil electrode in case of MSP-20-S01 during the cycle test in dimethylformamide (DMF) solution containing 0.5 $\mathrm{M} \mathrm{LiPF}_{6}$. The samples were analyzed between -2.8 and $+1.0 \mathrm{~V}$ with $10 \mathrm{mVs}^{-1}$ of scan rate. SCE: saturated calomel electrode.

20-S01 on the GCE as an active material. Fig. 7 shows one oxidation peak and three reduction peaks. The oxidation peak is located at $+0.51 \mathrm{~V}$ and the reduction peaks are located at -1.50 $\mathrm{V},-1.03 \mathrm{~V}$, and $-0.18 \mathrm{~V}$. In Fig. 7, in the cathodic process (i.e., backward scan), the peak current density of cycle 2 can be seen to be lower than that of cycle 5. This means that electroactivity decreases during the cycle test. In the cathodic process (i.e., backward scan), between $-1.50 \mathrm{~V}$ and $-1.03 \mathrm{~V}$, the peak current density of MSP-20-S01 is lower than that of MSP-20. This means that lithium polysulfides can be made between intercalated Li-ion and sulfur in the porous carbon structure.

In Fig. 8, we used Al foil as an electrode. There was MSP20 -S01 on the Al foil as an active material. Fig. 8 shows two oxidation peaks and one reduction peak. The oxidation peaks are located at $-0.83 \mathrm{~V}$ and $+0.64 \mathrm{~V}$ and the reduction peak is located at -0.96 V. In Fig. 8, in the cathodic process (i.e., backward scan), we were able to see two oxidation peaks. The two oxidation peaks of cycle 2 disappear during the cycle test, so there are no oxidation peaks in the $\mathrm{CV}$ graph of cycle 5 . The peak current density of cycle 2 is lower than that of cycle 5 . This means that electroactivity decreases during the cycle test. The CV graph of cycle 5 has a slighter incline than that of cycle 2 . The important thing here is that the area of MSP-20-S01 is larger than that of MSP-20. This means that lithium polysulfides can be made between intercalated $\mathrm{Li}$-ion and sulfur in the porous carbon structure, so we were able to confirm more electroactivity.

When we compare Fig. 7 with Fig. 8, Fig. 7 shows more curves of peak current density than does Fig. 8. Because GCE was made with graphite, the surface of GCE doesn't react with Li-ion. So, in detail, Fig. 7 can show lithium polysulfides that can be made between intercalated Li-ion and sulfur in a porous carbon structure. However, in Fig. 8, because MSP-20-S01 was placed on one side of the $\mathrm{Al}$ foil, $\mathrm{Li}$-ion can be attached to the other side of the $\mathrm{Al}$ foil. So, Fig. 8 shows less lithium polysulfide than does Fig. 7.

\section{Conclusions}

In this study, AC-S composite was prepared through an infiltration method using an organic solvent. This simple preparation process can provide a promising route for cost-effective production of processible carbon materials. As a trapping carbon structure, $\mathrm{AC}$ can provide a porous structure for containing sulfur. Lithium polysulfides can be made between intercalated $\mathrm{Li}$-ion and sulfur in the porous carbon structure. We were able to confirm that the AC-S composite electrode had current density superior to that of the AC electrode. From the electrochemical characterizations, we were able to confirm that the AC-S composite can be an effective cathode candidate material for $\mathrm{Li}-\mathrm{S}$ batteries.

\section{Acknowledgments}

This research was partly supported by the Inha University through the Korea Institute for Advancement of Technology, Korea (Wide-range Economic Core Institute Project 2012, Preparation and Application of High Performance Artificial Graphite, Grant No.: R0001858). This research was partly supported by the Ministry of Education, Science and Technology (Korea) (Nuclear Power Research Base Development Project, Grant No. 2012M2B2A4029894).

\section{References}

[1] Orlikova B, Diederich M. Power from the garden: plant compounds as inhibitors of the hallmarks of cancer. Curr Med Chem, 19, 2061 (2012). http://dx.doi.org/10.2174/092986712800228998.

[2] Kolosnitsyn VS, Karaseva EV. Lithium-sulfur batteries: problems and solutions. Russ J Electrochem, 44, 506 (2008). http://dx.doi. org/10.1134/S1023193508050029.

[3] Wang H, Yang Y, Liang Y, Robinson JT, Li Y, Jackson A, Cui Y, Dai H. Graphene-wrapped sulfur particles as a rechargeable lithium-sulfur battery cathode material with high capacity and cycling stability. Nano Lett, 11, 2644 (2011). http://dx.doi.org/10.1021/ 
n1200658a.

[4] Liang C, Dudney NJ, Howe JY. Hierarchically structured sulfur/ carbon nanocomposite material for high-energy lithium battery. Chem Mater, 21, 4724 (2009). http://dx.doi.org/10.1021/ cm902050j.

[5] Zheng G, Yang Y, Cha JJ, Hong SS, Cui Y. Hollow carbon nanofiber-encapsulated sulfur cathodes for high specific capacity rechargeable lithium batteries. Nano Lett, 11, 4462 (2011). http:// dx.doi.org/10.1021/nl2027684.

[6] Elazari R, Salitra G, Garsuch A, Panchenko A, Aurbach D. Sulfurimpregnated activated carbon fiber cloth as a binder-free cathode for rechargeable Li-S batteries. Adv Mater, 23, 5641 (2011). http:// dx.doi.org/10.1002/adma.201103274.

[7] Liang J, Jiao Y, Jaroniec M, Qiao SZ. Sulfur and nitrogen dualdoped mesoporous graphene electrocatalyst for oxygen reduction with synergistically enhanced performance. Angew Chem Int Ed, 51, 11496 (2012). http://dx.doi.org/10.1002/anie.201206720.

[8] Ahmadi R, Amini MK. Synthesis and characterization of Pt nanoparticles on sulfur-modified carbon nanotubes for methanol oxidation. Int J Hydrogen Energy, 36, 7275 (2011). http://dx.doi. org/10.1016/j.ijhydene.2011.03.013.

[9] Wang C, Chen JJ, Shi YN, Zheng MS, Dong QF. Preparation and performance of a core-shell carbon/sulfur material for lithium/ sulfur battery. Electrochim Acta, 55, 7010 (2010). http://dx.doi. org/10.1016/j.electacta.2010.06.019.

[10] Hummers WS, Offeman RE. Preparation of graphitic oxide. J Am Chem Soc, 80, 1339 (1958). http://dx.doi.org/10.1021/ ja01539a017.

[11] Wu ZS, Ren W, Gao L, Liu B, Jiang C, Cheng HM. Synthesis of high-quality graphene with a pre-determined number of layers. Carbon, 47, 493 (2009). http://dx.doi.org/10.1016/j.carbon. 2008.10.031.

[12] Park SE, Park SJ, Kim S, Preparation and capacitance behaviors of cobalt oxide/graphene composites. Carbon Lett, 13, 130 (2012). http://dx.doi.org/10.5714/CL.2012.13.2.130.

[13] Shin D, Bae SK, Yan C, Kang JM, Rye JC, Ahn JH, Hong BH. Synthesis and applications of graphene electrodes. Carbon Lett, 13 1 (2012). http://dx.doi.org/10.5714/CL.2012.13.1.001.

[14] Li D, Muller MB, Gilje S, Kaner RB, Wallace GG. Processable aqueous dispersions of graphene nanosheets. Nat Nanotechnol, $\mathbf{3}$ 101 (2008). http://dx.doi.org/10.1038/nnano.2007.451.

[15] Lu Y, Wang Y, Zou Y, Jiao Z, Zhao B, He Y, Wu M. Macroporous $\mathrm{Co}_{3} \mathrm{O}_{4}$ platelets with excellent rate capability as anodes for lithium ion batteries. Electrochem Commun, 12, 101 (2010). http://dx.doi. org/10.1016/j.elecom.2009.10.046.

[16] Yan J, Wei T, Qiao W, Shao B, Zhao Q, Zhang L, Fan Z. Rapid microwave-assisted synthesis of graphene nanosheet $/ \mathrm{Co}_{3} \mathrm{O}_{4} \mathrm{com}$ posite for supercapacitors. Electrochim Acta, 55, 6973 (2010). http://dx.doi.org/10.1016/j.electacta.2010.06.081.

[17] Lebegue E, Baranton S, Coutanceau C. Polyol synthesis of nanosized $\mathrm{Pt} / \mathrm{C}$ electrocatalysts assisted by pulse microwave activation. J Power Sources, 196, 920 (2011). http://dx.doi.org/10.1016/j. jpowsour.2010.08.107.

[18] Yang S, Cui G, Pang S, Cao Q, Kolb U, Feng X, Maier J, Mullen K. Fabrication of cobalt and cobalt oxide/graphene composites: towards high-performance anode materials for lithium ion batteries. ChemSusChem, 3, 236 (2010). http://dx.doi.org/10.1002/ cssc. 200900106

[19] Misoon O, Seok K. Effect of dodecyl benzene sulfonic acid on the preparation of polyaniline/activated carbon composites by in situ emulsion polymerization. Electrochim Acta, 59, 196 (2012). http:// dx.doi.org/10.1016/j.electacta.2011.10.058.

[20] Park S, Kim S. Effect of carbon blacks filler addition on electrochemical behaviors of $\mathrm{Co}_{3} \mathrm{O}_{4}$ /graphene nanosheets as a supercapacitor electrodes. Electrochim Acta, 89, 516 (2013). http://dx.doi. org/10.1016/j.electacta.2012.11.075. 